\title{
FOTOGRAFIA E MODA: REFLEXÕES SOBRE O TER NA CONSUMAÇÃO DO
}

\section{SER}

\author{
Athos da Silva Santos ${ }^{1}$ \\ Vinicius Ferreira Pinto ${ }^{2}$ \\ Marcia Braga Capovilla ${ }^{3}$
}

\begin{abstract}
Resumo
A efemeridade e o excesso do consumo na moda atendem às necessidades do mercado e do sistema econômico vigente, uma vez que este demanda a rotatividade de produtos. Neste sentido, cumpre eficiente papel a obsolescência programada que pode vir instaurada tanto em aspectos de qualidade física, quanto em aspectos de qualidade estética que é um precípuo da moda. A identificação com os padrões excessivos de consumo torna-se um aporte central para a indústria da moda que historicamente utiliza a imagem fotográfica para este fim. Desta forma, o presente trabalho propõe reflexões sobre os valores inseridos no consumo, a partir de uma revisão bibliográfica subsidiada pela criação de um catálogo de fotografias que faz uso da própria linguagem publicitária. $\mathrm{O}$ estudo nos permite inferir a necessidade de questionar o consumo irracional e reconhecer a fotografia de moda como instrumento também de transformação da realidade social e autoconhecimento do sujeito no mundo.

Palavras-chave: fotografia de moda. Consumo. Estética.

\section{PHOTOGRAPHY AND FASHON: REFLECTIONS ABOUT HAVING IN THE CONSUMMATION OF BEING}

\begin{abstract}
The efemerity and the excess of consumption in fashion meets the needs of the market and the current economic system, since this demand the turnover of products. In this sense, the programmed obsolescence fulfills the efficient role that can be instituted both in aspects of physical quality, and in aspects of aesthetic quality which it is a primary for the fashion. The identification with the excessive patterns of consumption becomes a central contribution to the fashion industry that historically uses the photographic image for this purpose. Thus, the present work proposes reflections on the values inserted in consumption, from a bibliographic review subsided by the creation of a catalogue of photographs that makes use of the advertising language itself. The study allows us to infer the need to question irrational consumption and to recognize fashion photography as an instrument for transforming the social reality and self-knowledge of the subject in the world.
\end{abstract}

Keywords: photography of fashion. Consumption. Aesthetics.

\footnotetext{
${ }^{1}$ Universidade Vila Velha (UVV), Vila Velha - Espírito Santo - Brasil. Graduado em Comunicação Social (com ênfase em Publicidade e Propaganda) e em Fotografia pela Universidade Vila Velha (UVV). ORCID $<$ https://orcid.org/0000-0001-6147-9850>. E-mail: athosdasilvasantos@gmail.com.

${ }^{2}$ Escola Estadual de Ensino Fundamental e Médio Benício Gonçalves, Secretaria de Educação do Estado do Espírito Santo, Vila Velha - Espírito Santo - Brasil. Mestre em Cognição e Linguagem pela Universidade Estadual do Norte Fluminense Darcy Ribeiro (UENF). É professor de Ciências/Biologia na Educação Básica. ORCID <http://orcid.org/0000-0001-9016-5279>. E-mail: vinicius.uenf@gmail.com.

${ }^{3}$ Universidade Vila Velha (UVV), Vila Velha - Espírito Santo - Brasil. Graduada em Artes Plásticas pela Universidade Federal do Espírito Santo (UFES) e Especialista em Design de Moda pela Universidade Vila Velha (UVV). Coordenadora e professora do Curso Superior de Tecnologia em Fotografia da UVV. ORCID $<$ https://orcid.org/0000-0001-6524-4637>. E-mail: marciac@uvv.br.
} 


\section{Linguagens - Revista de Letras, Artes e Comunicação - ISSN 1981- 9943 \\ Blumenau, v. 14, n. 2, p. 128-142, maio/ago. 2020 \\ DOI: http://dx.doi.org/10.7867/1981-9943.2020v14n2p128-142}

\section{INTRODUÇÃO}

Vivemos e presenciamos cotidianamente a busca exaustiva por inserção na moda e sua importância, assim como aquela dada aos padrões corporais estabelecidos e determinados por uma indústria que se tornou ditadora de signos de felicidade (FERRAZ et al., 2007).

A afirmação supracitada vai ao encontro do fato deste empreendimento criar signos que identificam as pessoas como detentores de um ou outro bem e que por tal motivo são felizes. Os diferentes estratos sociais podem ser representados por símbolos e marcas, e essa busca por pertencimento, aceitação de determinado grupo social presume a identificação com seus signos. A compra de peças falsificadas com estampas, em muitos casos exageradas, de marcas famosas e que costumam ter alto custo, exprime a imposição de uma cultura elitista ostentatória (GONÇALVES; PAULA, 2018).

De acordo com Trinca (2008), as características da modernidade surgem, sobretudo, mas não exclusivamente, a partir dos processos de urbanização, com o desenvolvimento mercantil, e, principalmente, a partir do fenômeno de industrialização da Revolução Industrial Inglesa. A urbanização impôs um novo ritmo para esta sociedade sob o domínio do capital, aspecto que foi essencial para a consolidação da cultura do consumo.

A felicidade tem seu caminho ditado pelo estrato social que domina o mercado midiático e o mercado a partir da moda. A busca pela felicidade tem, portanto, um caminho tortuoso e difícil para aqueles que não se enquadram e que acabam sendo excluídos e marginalizados. Ferraz et al. (2007) afirmam que estes paradigmas de felicidade instaurados na sociedade contemporânea, vão de encontro a ideia de que "valores são ineficazes na busca da felicidade" como sugerem alguns estudos (FERRAZ et al., 2007, p. 241). Assim, levantar o debate na sociedade sobre a relação entre a felicidade, ou a simples sensação de prazer, e os padrões de consumo é urgente.

Ribeiro (2015) relata que os bens materiais estão ligados às declarações de felicidade corroborando com seus estudos anteriores e acrescentando que no Brasil os bens relacionais são fundamentais para o reconhecimento de felicidade. Nesse sentido, pode-se incluir discussões como pertencimento e identidade e a relação entre os bens materiais e os bens relacionais.

Nesse contexto, o presente trabalho compreende uma produção bibliográfica e fotográfica que aborda a fotografia de moda, seu simbolismo e o consumo excessivo através da qual expressa quem é pelo que usa e pela quantidade de itens que possui. Desta forma, procura-se estimular nos envolvidos, expectadores/leitores ou não, uma reflexão sobre o 


\section{Linguagens - Revista de Letras, Artes e Comunicação - ISSN 1981- 9943 \\ Blumenau, v. 14, n. 2, p. 128-142, maio/ago. 2020 \\ DOI: http://dx.doi.org/10.7867/1981-9943.2020v14n2p128-142}

conceito de felicidade, consumo compulsório e a construção de uma identidade pautada na realidade, dentro da valorização do ser, em detrimento do ter.

\section{DESENHO METODOLÓGICO}

Para atingir ao objetivo proposto, foi desenvolvido um catálogo que através da fotografia publicitária de moda, busca suscitar a reflexão e discussão sobre os temas abordados. No campo da fotografia publicitária, Camilo (2005) diferencia dois principais paradigmas: o paradigma da ostentação e o da encenação. No primeiro ocorre centralidade no produto com iluminação que subtraia suas sobras a fim de tirar qualquer aspecto que possa causar distração, mesmo com a presença de atores publicitários o objeto é o centro, existe também uma busca pelo hiper-realismo. O segundo, como o próprio nome sugere, ocorre toda uma encenação que tira a centralidade do objeto que ainda deve dividir a atenção do espectador com os atores, com o cenário e até mesmo com a história. Enquanto no primeiro o espaço recebe significativa importância, no segundo o foco é o tempo, uma vez que busca colocar o produto em uma história inserindo-o em contextos de qualidades morais (CORDEIRO, 2006).

O presente trabalho utiliza aspectos da fotografia publicitária dentro do paradigma da encenação para representar não um produto específico, mas preceitos éticos e morais que poderão ser (re)pensados, inclusive em suas perspectivas estéticas.

A fotografia publicitária tem como característica principal a intencionalidade na escolha do cenário, da pose, da iluminação, entre outros componentes. $\mathrm{O}$ uso dos recursos computacionais para correção e manipulação do real também costuma ser instrumento deste tipo de fotografia, entretanto a modificação drástica da realidade ou mesmo dos seus signos podem conduzir a certa dificuldade de identificação pelo observador (CORDEIRO, 2006).

Ao tentar situar a fotografia no contexto da moda precisamos considerar seu caráter efêmero e exagerado (LIPOVESTKY, 1989); sensível e imaginativo (DE CARLI, 2002), tais aspectos exigem, por vezes, que o fotógrafo faça uso de ferramentas que intensifiquem as sensações explorando os mais diversos campos da psique humana. Neste contexto, De Carli (2002, p. 177) afirma que "som, luz, imagens, ambiente desviam a realidade, trabalhando o ambiente e o corpo a serviço da moda, com todos os artifícios técnicos e tecnológicos possíveis". Assim, a fotografia da moda trabalha com a dualidade do real, com viés para além do natural, mas sobretudo, do imaginário artificial sensível. 


\section{Linguagens - Revista de Letras, Artes e Comunicação - ISSN 1981- 9943 \\ Blumenau, v. 14, n. 2, p. 128-142, maio/ago. 2020 \\ DOI: http://dx.doi.org/10.7867/1981-9943.2020v14n2p128-142}

As fotografias produzidas neste trabalho fizeram uso dos artifícios da fotografia publicitária da moda com aspectos de encenação, através de um catálogo que não busca expor um produto físico, mas sim os valores ligados ao consumo: o exagero, o consumo pautado na efemeridade e no hedonismo. Estes aspectos da moral guiam, por vezes, a estética que aqui é colocada junto a sua etimologia, em resumo como sendo "a capacidade do humano de sentir a si próprio e ao mundo num todo integrado" (DUARTE, 2001, p. 13).

As fotografias produzidas foram influenciadas pelo trabalho do fotógrafo Danil Golovkin, de origem russa e residente de Moscou, considerado um dos principais nomes da Vogue Rússia, GQ e L'Officiel. Danil é formado em design gráfico e tem seu trabalho caracterizado pelo bom senso na iluminação e retrato (DOROFEEVA, 2013), a figura 1 e figura 2 apresentam um pouco do trabalho do Danil Golovkin.

Figura 1. Foto de Danil Golovkin.

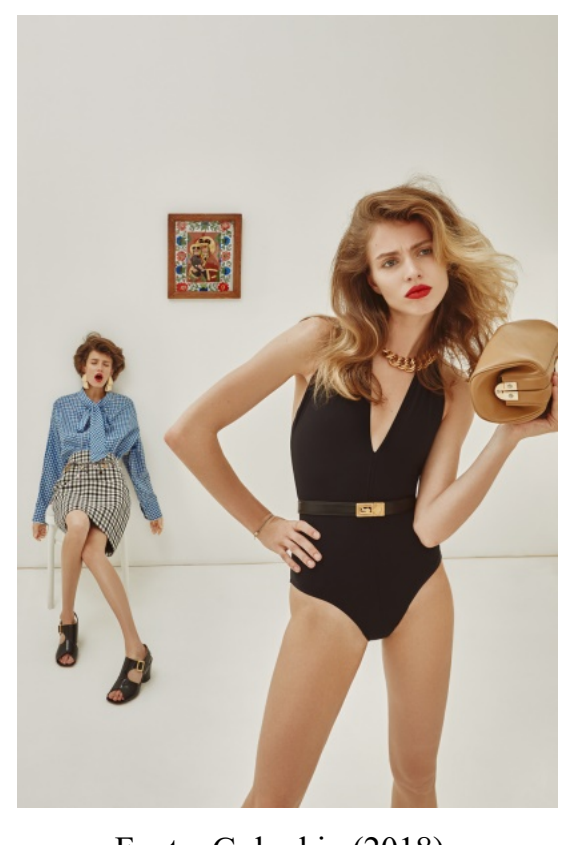

Fonte: Golovkin (2018).

Figura 2. Foto de Danil Golovkin.

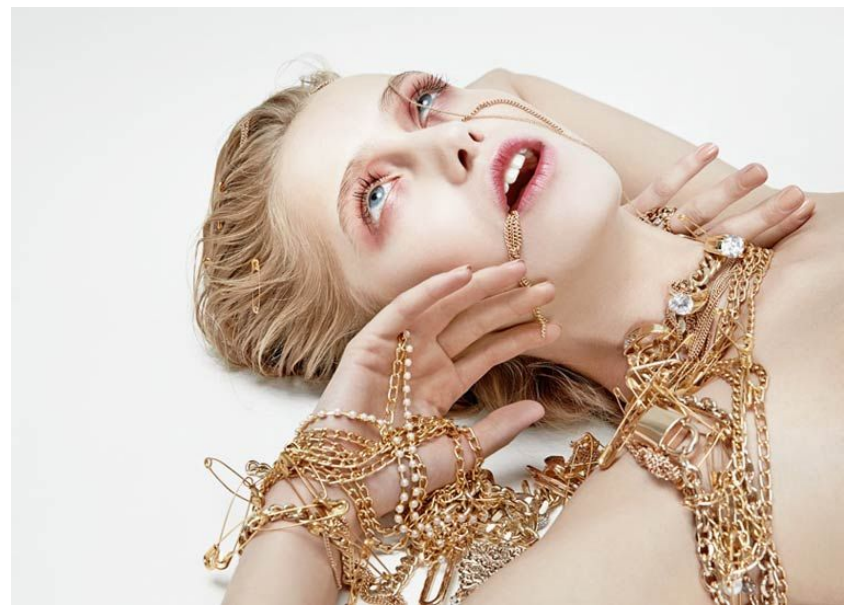


Além disso, também foi referência o trabalho do fotógrafo holandês, Erwin Olaf, cujas imagens contemporâneas traduzem sua obsessão pelas diferentes formas humanas, abalando valores mais tradicionais da sociedade atual (GARCIA, 2015). As figuras 3 e fotografia 4 são imagens produzidas pelo fotógrafo.

Figura 3. Foto de Erwin Olaf.

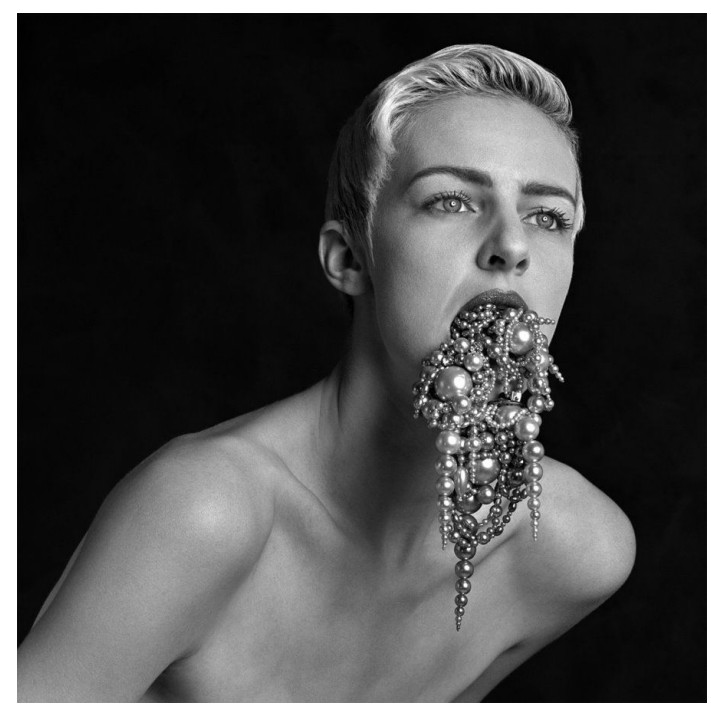

Fonte: Olaf (1986).

Figura 4. Foto de Erwin Olaf.

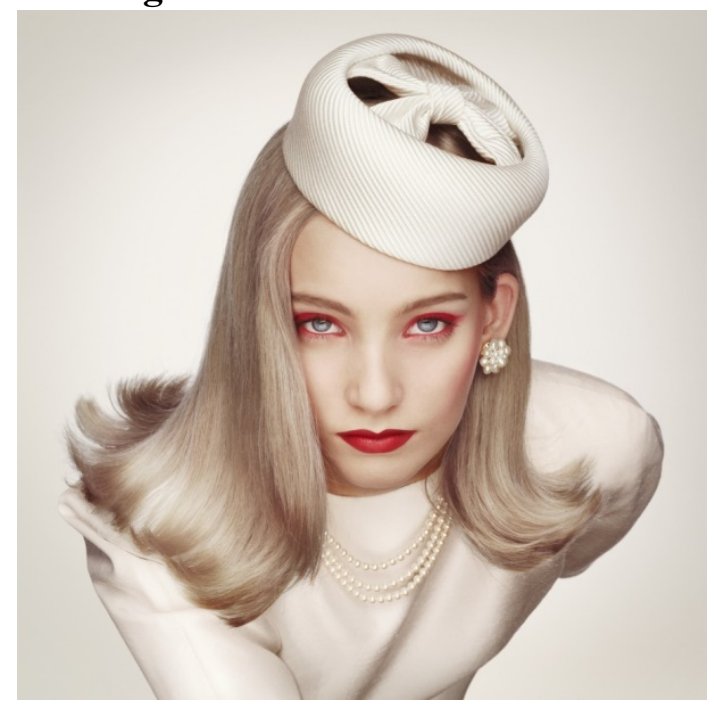

Fonte: Olaf (2000).

A produção de catálogo de fotografia faz-se necessária por considerarmos que a fotografia enquanto texto presume competências tanto do fotógrafo quanto do leitor. A 


\section{Linguagens - Revista de Letras, Artes e Comunicação - ISSN 1981- 9943 \\ Blumenau, v. 14, n. 2, p. 128-142, maio/ago. 2020 \\ DOI: http://dx.doi.org/10.7867/1981-9943.2020v14n2p128-142}

mensagem produzida pela fotografia parte tanto da expressão que se dedica ao espelho técnico e estético envolvidos na produção da imagem, quanto do conteúdo que é determinado pelas vivências, pelos sujeitos e suas historicidades (MAUAD, 2005).

A autora ainda afirma que a fotografia compõe a textualidade de uma época junto com outros textos de outras formas, assim as fotografias rompem também com o reducionismo de seu aspecto ilustrativo, podendo em determinadas condições se organizar em função de um tema (MAUAD, 2005). Assim, algumas fotografias produzidas no catálogo serão parte da textualidade deste trabalho, em resumo constituem pilar de sustentação empírica destas discussões.

A fotografia de moda emerge a partir do desenvolvimento das revistas de moda, Roça (2016) afirma que a partir de 1880 as revistas deixam de usar gravuras para passar a utilizar fotografias, em geral refletindo seu contexto histórico. Um importante instrumento de divulgação de produtos e tendências é o catálogo, que carrega consigo a responsabilidade de despertar o desejo pela compra. Pepicon e Soares (2010) indicam que o catálogo auxilia na divulgação da marca, da sua identidade e dos seus produtos.

Desta forma, ressaltamos que neste trabalho, a apresentação de imagens de um catálogo construído a luz destas discussões filosóficas e metodológicas, assim como seu próprio desenvolvimento terá como finalidade tanto a representação do impacto da fotografia da moda nas relações de consumo, quanto a busca pela reflexão de valores do consumo vinculados a ela, fazendo uso da própria linguagem imagética publicitária como estratégia de expressão em Mauad (2005), sobretudo em seus aspectos estéticos para compor a textualidade.

\section{A EFEMERIDADE E O EXCESSIVO NO CONSUMO DA MODA}

A obsolescência pode ser encarada como uma das maiores ferramentas do sistema econômico vigente para impulsionar o consumo. Packard (1965) afirma a obsolescência de desejabilidade ou psicológica como um dos três tipos dessa prática, neste caso a vontade de possuir determinado objeto que ainda permanece em bom estado de funcionamento, desaparece em função do surgimento de um novo, mesmo que possua igual funcionalidade, em geral o conceito de novo passa a ser associado ao conceito de melhor.

A moda provavelmente deve ter papel central na obsolescência psicológica, servindo-se da linguagem publicitária e propriamente da fotografia publicitária de moda que acaba por auxiliar, sobretudo na localização temporal, social e identitária do objeto a ser vendido. 


\section{Linguagens - Revista de Letras, Artes e Comunicação - ISSN 1981- 9943 \\ Blumenau, v. 14, n. 2, p. 128-142, maio/ago. 2020 \\ DOI: http://dx.doi.org/10.7867/1981-9943.2020v14n2p128-142}

Bauman (2007, p. 111) aponta que a "síndrome consumista é uma questão de velocidade, excesso e desperdício". A velocidade com que as novidades nos são apresentadas representam também uma estratégia de hipervalorização do consumo que vai além do simples ato de comprar objetos e bens em geral e perpassa também a assimilação de imagens e valores (PADILHA, 2006). Esta perspectiva também está em consonância com a definiç̧ão de Taschner (1997) de que a cultura de consumo "é todo um conjunto de imagens e símbolos que vão sendo criados e recriados, associados a esses bens, além de novas formas de comportamento efetivo e no modo de pensar e sentir de segmentos cada vez mais amplos da população da chamada sociedade ocidentais" (TASCHNER, 1997, p. 28.).

Pensando no contexto deste trabalho, precisamos diferenciar a indústria do objeto em si (vestuário, acessório, sapato etc.), aquele com foco na venda do produto, da indústria da moda que não se rende a simples comercialização de um produto físico, mas sim de seus signos, algo intangível (HOEKS, 2006 apud ROCHA, 2012). Bourdieu (1998) nos traz a ideia de que o capital econômico se traduziria também em um capital cultural, pensando no contexto da sociedade de consumo certos conceitos que dependem de um mercado, como por exemplo, o conceito de beleza que estaria ligado ao mercado da moda e também às relações societárias de poder. Nesse sentido, Featherstone (1995) indica que "Se é possível afirmar o funcionamento de uma lógica do capital derivada da produção, talvez seja possível afirmar também uma 'lógica do consumo', que aponta para os modos socialmente estruturados de usar bens para demarcar relações sociais" (FEATHERSTONE,1995, p. 35).

As figuras 5 e 6 compreendem algumas imagens produzidas no contexto deste trabalho e foram desenvolvidas a partir das leituras sobre o excessivo e sobre o ter, embebidas de representações mercadológicas dos desejos, ou mesmo do desenvolvimento deles.

Figura 5. Foto de Athos Santos (2018).

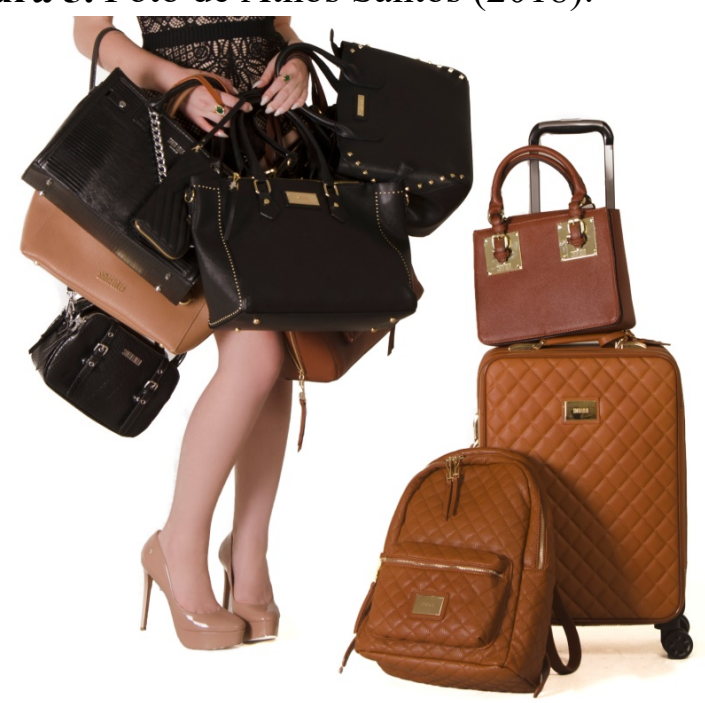


Fonte: arquivo próprio.

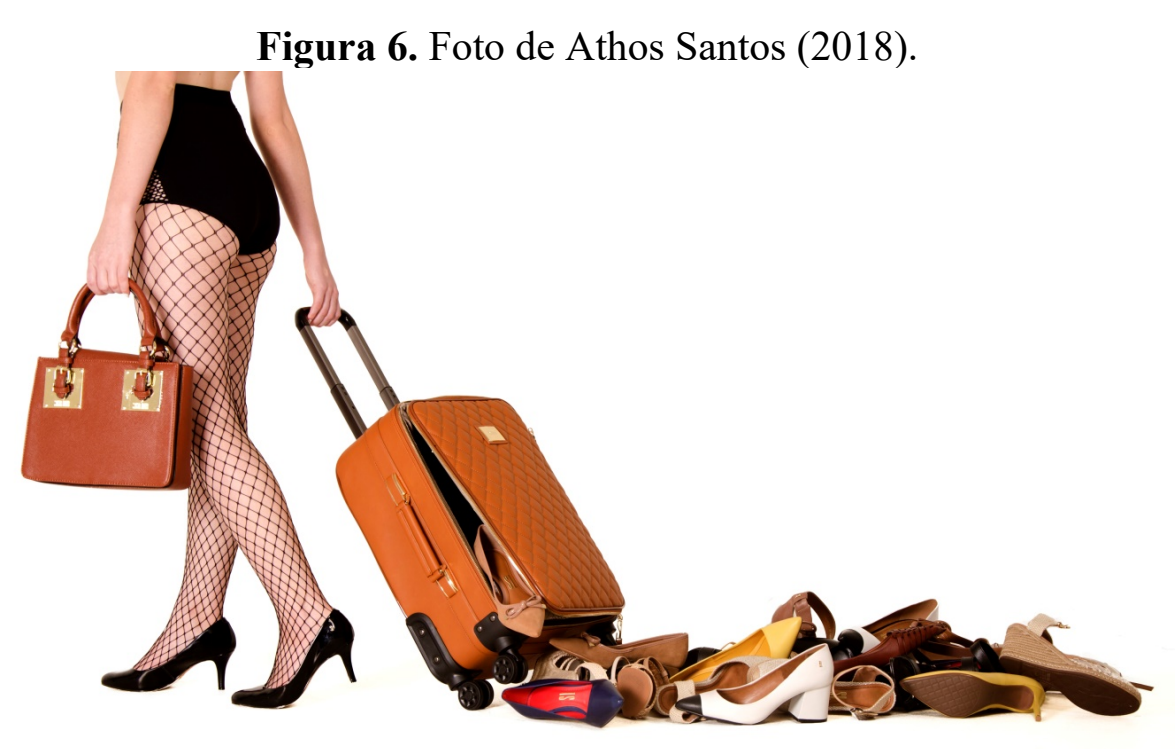

Fonte: os autores.

Neste sentido, através do processo de criação do projeto podemos refletir e entender o mercado da moda como um desenvolvedor de signos, ao critério daquele que os determinam o mercado, o qual busca imprimir ao indivíduo pertencimento a um ou outro estrato social.

$\mathrm{Na}$ fotografia podemos encontrar duas realidades, na primeira temos o referente que se produz intencionalmente, e na segunda a imagem produzida. A segunda realidade geralmente se sobrepõe a primeira e permanece no tempo com maior facilidade em tornar-se documento, trata-se de uma imagem polissêmica (RODRIGUES, 2007).

Ainda considerando o que Mauad (2005) afirma sobre as diversas possibilidades de interpretação de uma imagem, o conteúdo dependerá das vivências e experiências historicamente construídas pelo leitor/observador. Assim, temos nas figuras 5 e 6 dentro de uma primeira realidade em Rodrigues (2007), ou da expressão em Mauad (2005), a busca pela representação do glamour no excessivo, do ter, da relação entre um esse ter e a identidade que ele representa.

Os signos de poder, expressos pelas marcas dos bens de consumo, nos remetem ao conceito de persona, máscaras utilizadas no teatro grego para designar uma característica, compreendido pela psicologia analítica como máscaras não reais utilizadas por um indivíduo para identificação e pertencimento de conteúdos desejados (FARIAS; MONTEIRO, 2012).

As marcas dos produtos funcionam como uma persona com o objetivo de identificar aquele indivíduo ao grupo social pretendido. Bourdieu (1998) nos remete a ideia de que o status estaria ligado a possibilidade de desfrutarmos de certos bens, assim as marcas em voga, 


\section{Linguagens - Revista de Letras, Artes e Comunicação - ISSN 1981- 9943 \\ Blumenau, v. 14, n. 2, p. 128-142, maio/ago. 2020 \\ DOI: http://dx.doi.org/10.7867/1981-9943.2020v14n2p128-142}

representando signos de uma determinada classe social, conferiria aquele que o possui certo status. A busca por esse status vai além da busca pelos benefícios que ele permitiria, estas características são vendidas pela mídia a serviço do mercado como ideário de felicidade.

A fotografia procura eternizar um momento, sendo assim ela garante que a moda fique viva, uma vez operando como documento ela pode contar a sua evolução, agindo assim inclusive como reprodutora da moda como sugere Maia (2014).

A fotografia de moda é uma das formas de levar o consumidor a adquirir o produto e pode ser capaz de atuar no campo do imaginário, refletindo e induzindo comportamentos. Vargas (2008) e Santos (2009) sugerem que a fotografia de moda não tem obrigação com o real, uma vez que para além de mostrar um modo de se vestir e propagar produtos, esse ramo também exige despertar o imaginário e o sonho de quem contempla.

Uma boa fotografia de moda a serviço do excessivo no mercado em geral contém uma parte de sonho, que seduz e transporta seu público no universo do belo e da suprema elegância, através da apresentação das mais novas criações da moda. A fotografia de moda excepcional é aquela que é oportuna, ao mesmo tempo em que aspira eternidade (VARGAS, 2008).

Na perspectiva de Santos (2009), a moda se comunica através de diversas formas como em editoriais que levam uma tendência a partir de imagens associadas a textos de cunho jornalístico, enquanto uma segunda abordagem se aproxima mais de uma campanha publicitária que expõe todo um ambiente favorável ao consumo. Nas palavras da autora o consumidor por vezes não questiona ou reflete a imagem, em geral "ele simplesmente vê, deseja e adquire.” (SANTOS, 2009, p. 1136).

\subsection{A INQUIETUDE DA FOTOGRAFIA DE MODA NA ESTÉTICA E NO CONSUMO}

“Cogito, ergo sum” (Descartes) ${ }^{4}$

A célebre frase supracitada nos permite iniciar nossas discussões sobre o existir na sociedade de consumo. Em resumo, Descartes propõe que uma certeza do nosso existir está pautada na dúvida decorrente do pensamento (VILELA; IZIDORO, 2013).

Baseada no contexto da sociedade pós-moderna, a afirmação de Barbosa (2006) de que consumir é tão fundamental que podemos viver sem produzir, mas não sem consumir, nos faz

\footnotetext{
${ }^{4}$ Em tradução livre para o português, a frase de Descartes significa "penso, logo existo".
} 


\section{Linguagens - Revista de Letras, Artes e Comunicação - ISSN 1981- 9943 \\ Blumenau, v. 14, n. 2, p. 128-142, maio/ago. 2020 \\ DOI: http://dx.doi.org/10.7867/1981-9943.2020v14n2p128-142}

questionarmo-nos sobre em que medida existimos para os outros na sociedade do consumo. Existimos pelas dúvidas geradas em função do nosso ser ou em função do que consumimos? Considerando ainda que o consumo viabiliza inúmeras relações sociais que permitiriam gerar reflexões.

Em meio a essa buliçosa irresolução sobre o existir na sociedade centralizada no consumo que corresponde ao alicerce fundamental do atual paradigma econômico, torna-se imprescindível levantar reflexões sobre os aspectos do consumo irracional guiado por uma estética criada por grupos hegemônicos.

As figuras 7 e 8 compreendem também parte da produção fotográfica criada sobre os alicerces das (re)leituras, a respeito da relação entre a manutenção da estética dos altos padrões de consumo e a moda, com olhar específico para sua fotografia.

Figura 7. Foto de Athos Santos (2018).

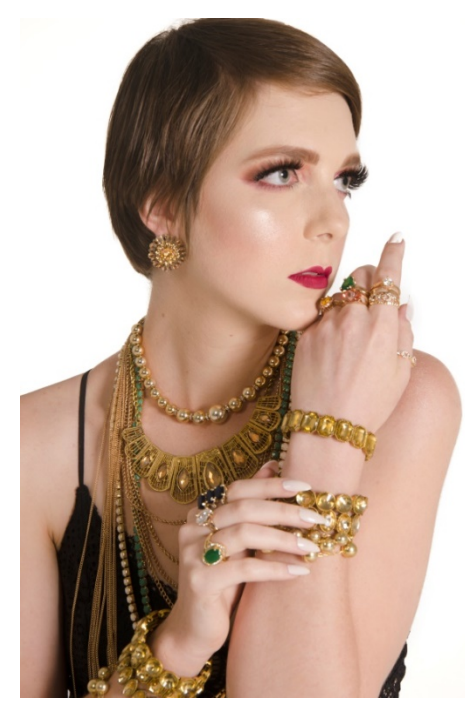

Fonte: os autores.

Figura 8. Foto de Athos Santos (2018).

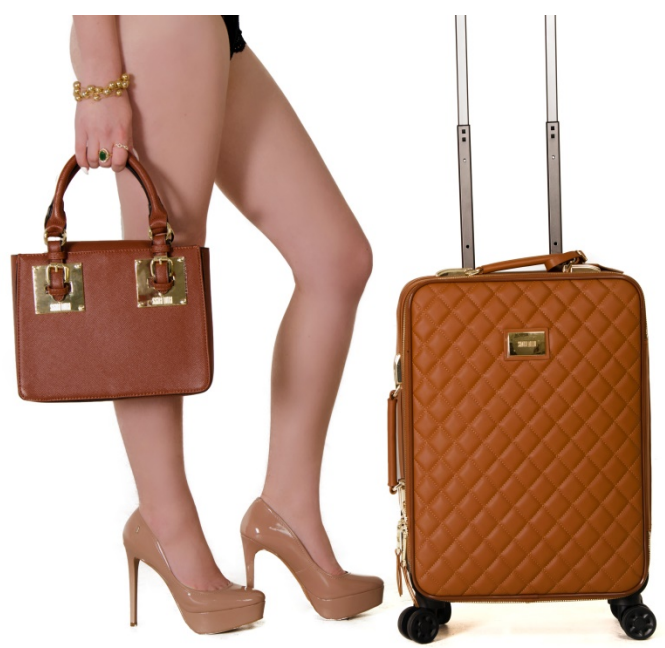




\section{Linguagens - Revista de Letras, Artes e Comunicação - ISSN 1981- 9943 \\ Blumenau, v. 14, n. 2, p. 128-142, maio/ago. 2020 \\ DOI: http://dx.doi.org/10.7867/1981-9943.2020v14n2p128-142}

Fonte: os autores.

As figuras 7 e 8 nos apresentam em uma primeira realidade (RODRIGUES, 2007), respectivamente, a ideia de posse do pertencimento e glamour na pseudo-sobriedade. Entretanto, tanto nas figuras 5 e 6 representadas anteriormente e quanto nas figuras 7 e 8 fica a expectativa pela sensação, pelo conteúdo (MAUAD, 2005) ou ainda pela segunda realidade (RODRIGUES, 2007) que coloca em evidência o que aqui discutimos pela textualidade fotográfica ou não.

A palavra estética tem origem do grego "aisthesis" que significa sentir, seu oposto é anestesia que representa a perda dos sentidos e das sensações (DUARTE, 2001), desta forma percebe-se que a estética está diretamente ligada ao sentir, à sensibilidade e ao reconhecimento de si própria no mundo. É neste contexto que emerge a necessidade de discutirmos o conceito de representatividade e identidade na moda a partir da fotografia na atualidade.

Em entrevista concedida a revista Veja (2001), Andrea Jung, então presidente mundial da Avon, empresa ligada ao ramo dos cosméticos, presente em mais 140 países, afirma que em determinada pesquisa realizada pela empresa com 30.000 mulheres, em diversos países, $82 \%$ das entrevistadas disseram que os "produtos de beleza são uma necessidade, e não um luxo. A vaidade é um valor universal.” (TEIXEIRA, 2001).

Teixeira (2001) ainda aponta inúmeras pesquisas que demonstram como a beleza, ou o padrão imposto, pode trazer compensações e benefícios para quem a possui, desde ao abrandar de uma pena em função de condenação até a estratégia para atrair empreendimentos. Neste contexto, percebemos o quanto seguir padrões impostos é importante para a manutenção de diversas relações sociais nos mais variados setores, essa importância é dominada pelo mercado que promove o consumo.

Ao encontro destes preceitos caminham as propostas capitalistas que buscam transformar tudo em mercadoria alicerçando assim o fenômeno da supervalorização da beleza, ou da apropriação do belo. A mercantilização da estética em seu sentido etimológico nos permite compreender que "é dentro de uma cultura capitalista que é possível produzir exclusão para vender inclusão" (SAMPAIO; FERREIRA, 2009, p. 137). Neste complexo emaranhado de relações é que as pessoas buscam a aceitação e a validação de suas identidades e pertencimento a um determinado grupo (SAMPAIO; FERREIRA, 2009). 


\section{Linguagens - Revista de Letras, Artes e Comunicação - ISSN 1981- 9943 \\ Blumenau, v. 14, n. 2, p. 128-142, maio/ago. 2020 \\ DOI: http://dx.doi.org/10.7867/1981-9943.2020v14n2p128-142}

Para tanto, a sociedade do consumo faz uso de todo um aparato ideológico que inclui desde instituições como a família, mas que têm nos meios de comunicação de massa seus maiores contribuintes (SAMPAIO; FERREIRA, 2009).

A fotografia da moda pode contribuir para esse aparelhamento do sistema que institui padrões de beleza, mas também pode contribuir para levantar críticas e fazer pensar, uma vez que, na perspectiva de Rosario e Pereira (2017) pode ser reconhecida como texto intrínseco a cultura contemporânea.

Silva (2019) demonstrou em seu trabalho de pesquisa que a moda pode ser instrumento de comunicação de modificações dos aspectos políticos e culturais na sociedade, por meio de redes de sociabilidade ela percebeu a possibilidade do dinamismo no olhar sobre beleza e pertencimento. Neste sentido, aqui reconhecemos a moda como possível instrumento de revolução que se torna mais acessível com o aumento da sociabilidade pelas redes, mas que ao mesmo tempo, assim como indica Silva (2019), o gigante mercado da moda tradicional pode fazer uso dessas novas perspectivas associada ao marketing, mantendo sua normalidade.

Pereira e Rosario (2015) sugerem, ao analisar o aspecto da corporeidade na fotografia da moda, que ela contribui não apenas para a representação, mas também para a apresentação, estando ora a serviço do espírito mercadológico e ora embebidos de aspectos de conflitos que promovem rupturas, inclusive estéticas.

Ao buscar discutir a complexidade da fotografia de moda como representação de algo que existe, e ao mesmo tempo como apresentação de algo novo que propõe ruptura, como nos remete Pereira e Rosario (2015), não se nega o seu aspecto mercadológico, mas insere-se dentro da produtividade humana tal como a arte e a cultura.

\section{CONSIDERAÇÕES FINAIS}

O consumidor pode ser entendido como um ator na sociedade, suas práticas, ou a ausência delas, deveriam ser encaradas como um ato político que poderia promover ainda quando coletivamente transformações sociais. Sabe-se que a velocidade das modificações sociais é vertiginosa, mas a cada dia que se passa a necessidade de (re)pensar sobre o agir emerge, sobretudo a partir das complexidades e adversidades decorrentes das desigualdades.

A fotografia da moda pode ser instrumento de manutenção do status quo, assim como fornecer mecanismos de transformação de uma realidade considerando as novas formas de relações sociais. O excessivo e a efemeridade são paradigmas que podem ainda ser perpetuados pelos agentes mantenedores desses axiomas, que desprezam a equidade e se 


\section{Linguagens - Revista de Letras, Artes e Comunicação - ISSN 1981- 9943 \\ Blumenau, v. 14, n. 2, p. 128-142, maio/ago. 2020 \\ DOI: http://dx.doi.org/10.7867/1981-9943.2020v14n2p128-142}

vestem de diverso e sustentável se for preciso em prol do seu objetivo central que é o consumo.

As influências e relações com o consumo no contexto que trazemos abrem margem para longa discussão, não se pretende com este trabalho encerrá-la, tão pouco limitá-la, talvez iniciar algumas reflexões a partir das fotografias produzidas que como se espera trazem sua própria narrativa tanto a partir do fotógrafo quanto do leitor.

As reflexões sobre o consumo na sociedade atual podem refletir inúmeras de suas mazelas, pobreza, estereótipos, exclusão, hedonismo, ansiedade e depressão, entretanto aqui propomos fazer uso da estética da própria fotografia publicitária de moda para levantarmos a bandeira do estímulo a autorreflexão e autoconhecimento do sujeito social.

\section{REFERÊNCIAS}

BARBOSA, L. Apresentação. In: BARBOSA, L.; CAMPBELL, C. (Org.). Cultura, consumo e identidade. Rio de Janeiro: Ed. FGV, 2006. 7-18 p.

BAUMAN, Z. O mal-estar da pós-modernidade. Rio de Janeiro: Jorge Zahar Editor, 1998.

. Vida líquida. Rio de Janeiro: Jorge Zahar Ed, 2007.

BOURDIEU, P. A economia das trocas simbólicas. 5. ed. São Paulo: Perspectiva,1998.

CAMILO, Eduardo J. M., Antonímias da fotografia publicitária: da ostentação à elisão dos objectos. Covilhã, Universidade da Beira Interior, Departamento de Comunicação e Artes/LABCOM, 2005.

CORDEIRO, R. Fotografia Publicitária e fotografia jornalística: pontos em comum. TCC do curso de Comunicação e Promoção: Teorias da publicidade, do mestrado em Ciências da Comunicação da Universidade da Beira Interior. 2006. Disponível em:

http://www.bocc.ubi.pt/pag/cordeiro-ricardo-fotografia-publicitaria.pdf acessado em: $25 / 11 / 2018$.

DE CARLI, A. M. S. O sensacional da moda. Caxias do Sul: EDUCS, 2002.

DOROFEEVA, E. 5 fashion photographers you need to know. The Russian Fashion Blog. 2013. Disponível em: http://www.russianfashionblog.com/index.php/2013/08/russianukrainian-fashion-photographers/\#axzz5XtafsQVJ, acessado em: 25/11/2018.

DUARTE, J. F. O sentido dos sentidos: a educação (do) Sensível. Curitiba: criar edições, 2001.

FARIAS, L. MONTEIRO, T. A identidade adquirida nas redes sociais através do conceito de persona. INTERCOM - Sociedade Brasileira de Estudos Interdisciplinares da

Comunicação, 2012. 
FEATHERSTONE, M. Cultura de consumo e pós-modernismo. São Paulo: Studio Nobel, 1995.

FERRAZ, R. B. TAVARES, H. ZILBERMAN, M. L. Felicidade: uma revisão. Revista de Psiquiatria Clínica. V. 34, n. 5, 2007.

GARCIA, W. Consumo e fotografia em Erwin Olaf: uma perspectiva comtemporânea.

Discursos fotográficos. Londrina, v.11, n.18. 2015.

GOLOVKIN, D. Addicted to glamour, 2014. Disponível em:

https://www.behance.net/danilgolovkin, acessado em: 23/05/2019.

. White room. Editorial online - Schön! Magazine, 10 de agosto de 2018, disponível em: https://schonmagazine.com/white-room/ acessado em: 23/05/2019.

GONÇALVES, V. D. PAULA, R. C. M. S. Comportamento dos consumidores de produtos falsificados: porque compram esse tipo de produto?. Marketing \& Tourism Review. V. 3, n. $2,2008$.

LIPOVETSKY, G. O império do efêmero: a moda e seu destino nas sociedades modernas. São Paulo: companhia das letras, 1989.

MAIA, K. FOTOGRAFIA DE MODA: Arte procedente da máquina. Revista Eletrônica de Moda. V. 2, n. 1, 2014.

MAUAD, A. M. Na mira do olhar: um exercício da análise da fotografia nas revistas ilustradas cariocas, na primeira metade do século XX. Anais do Museu Paulista. V. 13, n. 1, 2005.

OLAF, E. Pearls (Sabine), 1986. Disponível em: http://www.artnet.com/artists/erwinolaf/pearls-sabine-GDIaACyNfcrLmgJUqW24EA2 acessado em 23/05/2019.

Royal Blond. 2000. Disponível em:

https://www.erwinolaf.com/art/royal_blood_2000, acessado em: 23/05/2019.

PACKARD, V. Estratégia do desperdício. São Paulo: Ibrasa, 1965.

PADILHA, V. Shopping center: a catedral das mercadorias. São Paulo: Boitempo, 2006.

PEPICON, P. H. SOARES, B. N. Criação e conceituação do catálogo de moda da loja fluir Surf Skate Shop. Curso Superior de Design Gráfico (Monografia). Instituto Federal Fluminense - IFF. 2010.

PEREIRA, M. R. ROSARIO, N. M. As Rupturas de Sentido no Corpo na Fotografia Publicitária de Moda Contemporânea. Anais do INTERCOM - Sociedade Brasileira de Estudos Interdisciplinares da Comunicação. Rio de Janeiro: 2015.

RIBEIRO, C. A. C. Renda, relações sociais e felicidade no Brasil. DADOS - Revista de Ciências Sociais. Vol. 58, no 1, 2015. 
ROÇA, R. O. Fotografia de moda. (Monografia) Escola Focos Foto. São Paulo, 2016.

ROCHA, M. A. V. Moda e sustentabilidade: combinação possível?. Anais do VI Encontro Nacional de Estudos de Consumo, Rio de Janeiro-RJ: 2012. Disponível em:

http://www.estudosdoconsumo.com.br/artigosdoenec/ENEC2012-GT03-Rocha-

Moda_e_sustentabilidade.pdf. Acessado em: 08/10/2017.

RODRIGUES, R. C. Análise e tematização da imagem fotográfica. Ciência da Informação. V. 36, n. 3, 2007.

ROSARIO, N. M. PEREIRA, M. R. No limits na fotografia de moda: O Uber-corpo. Razón y Palabra. V. 21, n. 3. 2017.

SAMPAIO, R. P. A. FERREIRA, R. F. Beleza, identidade e mercado. Psicologia em revista. V. 15, n. 1, 2009.

SANTOS, E. B. Representações do catálogo de moda na sociedade e sua interferência sob o público-alvo mulher. Anais do II Encontro Nacional de Estudos da Imagem, Londrina-P, 2009.

SILVA, G. M. Corpo, política e emoção: feminismos, estética e consumo entre mulheres negras. Horizontes Antropológicos. V. 25, n. 54, 2019.

TASCHNER, G. Raízes da cultura do consumo. In: Revista USP - Dossiê Sociedade de Massa e Identidade. n. 32, dez./fev. 1996-97.

TEIXEIRA, S. A. Produção e consumo social da beleza. Horizontes Antropológicos. V. 7, n. $16,2001$.

TRINCA, T. P. O corpo-imagem na "cultura do consumo": uma análise histórico-social sobre a supremacia da aparência no capitalismo avançado. Dissertação (Mestrado), UNESP. Marília-SP: 2008.

VARGAS, C. Corpo e Imagem: um estudo sobre a construção da identidade feminina através da fotografia de moda da revista Vogue francesa dos anos 20 e 30. Campinas-SP: UNICAMP. 2008.

VILELA, A. N. O. IZIDORO, J. L. Os fundamentos da verdade no pensamento de René Descartes: uma relação à sua época, uma proposta à nossa época. CES Revista. Vol. 27. N. 21. 2013. 